\title{
Probabilistic description of ice-supersaturated layers in low resolution profiles of relative humidity
}

\author{
N. C. Dickson ${ }^{1}$, K. M. Gierens ${ }^{2}$, H. L. Rogers ${ }^{1}$, and R. L. Jones ${ }^{1}$ \\ ${ }^{1}$ Centre for Atmospheric Science, Department of Chemistry, University of Cambridge, Cambridge, UK \\ ${ }^{2}$ Deutsches Zentrum für Luft- und Raumfahrt, Institut für Physik der Atmosphäre, Oberpfaffenhofen, Germany \\ Received: 20 November 2009 - Published in Atmos. Chem. Phys. Discuss.: 1 February 2010 \\ Revised: 30 June 2010 - Accepted: 8 July 2010 - Published: 23 July 2010
}

\begin{abstract}
The global observation, assimilation and prediction in numerical models of ice super-saturated (ISS) regions (ISSR) are crucial if the climate impact of aircraft condensation trails (contrails) is to be fully understood, and if, for example, contrail formation is to be avoided through aircraft operational measures. Given their small scales compared to typical atmospheric model grid sizes, statistical representations of the spatial scales of ISSR are required, in both horizontal and vertical dimensions, if global occurrence of ISSR is to be adequately represented in climate models.

This paper uses radiosonde launches made by the UK Meteorological Office, from the British Isles, Gibraltar, St. Helena and the Falkland Islands between January 2002 and December 2006, to investigate the probabilistic occurrence of ISSR. Each radiosonde profile is divided into 50- and $100-\mathrm{hPa}$ pressure layers, to emulate the coarse vertical resolution of some atmospheric models. Then the high resolution observations contained within each thick pressure layer are used to calculate an average relative humidity and an ISS fraction for each individual thick pressure layer. These relative humidity pressure layer descriptions are then linked through a probability function to produce an s-shaped curve which empirically describes the ISS fraction in any average relative humidity pressure layer. Using this empirical understanding of the s-shaped relationship a mathematical model was developed to represent the ISS fraction within any arbitrary thick pressure layer. Two models were developed to represent both 50- and 100-hPa pressure layers with each reconstructing their respective s-shapes within $8-10 \%$ of the empirical curves. These new models can be used, to represent the small scale structures
\end{abstract}

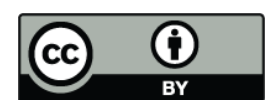

Correspondence to: N. C. Dickson (ncdickson@qinetiq.com) of ISS events, in modelled data where only low vertical resolution is available. This will be useful in understanding, and improving the global distribution, both observed and forecasted, of ice super-saturation.

\section{Introduction}

The global observation, assimilation and prediction in numerical models of ice super-saturated (ISS) regions (ISSR) are crucial if the climate impact of aircraft condensation trails (contrails) is to be fully understood, and if, for example, contrail formation is to be avoided through aircraft operational measures. A robust assessment of the global distribution of ISSR will further this debate, and ISS event occurrence, frequency and spatial scales have recently attracted significant attention (Spichtinger et al., 2003b; Gierens et al., 2004; Vaughan et al., 2005; Gettelman et al., 2006b; Rädel and Shine, 2007; Lamquin et al., 2009). The mean horizontal path length through ISSR, observed by MOZAIC aircraft, is $150 \mathrm{~km}( \pm 250 \mathrm{~km})$ (Gierens and Spichtinger, 2000). The average vertical thickness of ISS layers is $600-800 \mathrm{~m}( \pm 575 \mathrm{~m})$ but layers ranging from $25 \mathrm{~m}$ to $3000 \mathrm{~m}$ have been observed, with up to one third of ISS layers thought to be less than 100-m deep (Spichtinger et al., 2003a; Treffeisen et al., 2007). Given their small scales compared to typical model grid sizes, statistical representations of the spatial scales of ISSR are required, in both horizontal and vertical dimensions, if global occurrence of ISSR is to be adequately represented in climate models. Lamquin et al. (2009) showed the influence of model vertical resolution on the predicted occurrence of ISSR using the European Centre for Medium Range Weather Forecasts (ECMWF) Integrated Forecast System (IFS) on

Published by Copernicus Publications on behalf of the European Geosciences Union. 
both standard and high vertical resolution pressure levels, and also using radiosonde observations from a launch station in Lindenberg, Germany. Lamquin et al. (2009) linked the probability of at least one ISS event occurring within a thick pressure layer to the average relative humidity over the same layer. An s-shaped probability relationship was then suggested to describe the occurrence of ISS events in low vertical resolution pressure layers.

This paper aims to extend the research of Lamquin et al. to now link the ISS fractional occurrence within a given thick pressure layer (herein known as the ISS fraction) to the average relative humidity over that layer. This relationship is investigated for $50-\mathrm{hPa}$ and $100-\mathrm{hPa}$ thick pressure layers using high resolution vertical profiles of the atmosphere, specifically, radiosonde launches made by the UK Meteorological Office (UK Met Office) from the British Isles, Gibraltar, St. Helena and the Falkland Islands between January 2002 and December 2006. The ultimate aims of this research are to define both an empirical and mathematical description linking ISS fraction to average relative humidity within thick pressure layers. Both the empirical and mathematical descriptions presented here could be used to improve the prediction and representation of ISSR in climate models.

A similar problem, to the one discussed in this paper, occurs in relation to the satellite retrieval of relative humidity with respect to ice (RHi) within cirrus clouds $\left(\mathrm{RHi}_{\mathrm{c}}\right)$. While probability density functions (pdfs) of $\mathrm{RHi}_{\mathrm{c}}$, determined from in-situ observations, peak at 100-110\% (Ovarlez et al., 2002; Spichtinger et al., 2004), pdfs based on satellite data peak at consistently lower values of around 60-90\% (Gierens et al., 2004; Kahn et al., 2008, 2009; Lamquin et al., 2008). Therefore, the pdfs based on in-situ observations follow physical expectations (with $\mathrm{RHi}_{\mathrm{c}} \approx 100 \%$ ) while the satellite-derived pdfs do not. The most probable reason for this is that cirrus clouds are typically shallower than the satellite instruments vertical resolution, for example, nadir-sounders have a vertical resolution of up to $\sim 4 \mathrm{~km}$ for humidity. This is also true for a multi-channel instrument like the Atmospheric InfraRed Sounder, AIRS (Maddy and Barnet, 2008). Thus a shallow cloud layer with in-cloud ice saturation or supersaturation, but embedded within a subsaturated air mass (i.e. within the satellite vertical resolution), may result in an overall $\mathrm{RHi}_{\mathrm{c}}$ well below $100 \%$. This is suggested in Lamquin et al. (2008) where the pdf peak approaches an RHi of $100 \%$ with increasing cloud depth. It may be that the correction procedure derived in the present study would work in a similar way for this related satellite problem, however, this analysis is not included in this paper.
Table 1. A summary of UK Met Office high resolution radiosonde observations (1 January 2002-31 December 2006) used in this study. Observations were generally performed using the Vaisala RS80 up to mid-2005 with the RS92 instrument used thereafter (UK Meteorological Office).

\begin{tabular}{lrrcc}
\hline Station & \multicolumn{2}{c}{ Location } & $\begin{array}{c}\text { Launches } \\
(2002-2006)\end{array}$ & Radiosonde type \\
\hline Albemarle & $1.88^{\circ} \mathrm{W}$ & $55.02^{\circ} \mathrm{N}$ & 3546 & RS80/RS92 \\
Camborne & $5.329^{\circ} \mathrm{W}$ & $50.218^{\circ} \mathrm{N}$ & 3981 & RS80/RS92 \\
Castor Bay & $6.503^{\circ} \mathrm{W}$ & $54.503^{\circ} \mathrm{N}$ & 3234 & RS80/RS92 \\
Herstmonceux & $0.319^{\circ} \mathrm{W}$ & $50.89^{\circ} \mathrm{N}$ & 3771 & RS80/RS92 \\
Lerwick & $1.183^{\circ} \mathrm{W}$ & $60.139^{\circ} \mathrm{N}$ & 3957 & RS80/RS92 \\
Watnall & $1.25^{\circ} \mathrm{W}$ & $53.005^{\circ} \mathrm{N}$ & 3804 & RS80/RS92 \\
Gibraltar & $5.35^{\circ} \mathrm{W}$ & $36.15^{\circ} \mathrm{N}$ & 3429 & RS80 \\
St Helena & $5.667^{\circ} \mathrm{W}$ & $15.933^{\circ} \mathrm{S}$ & 1189 & RS80 \\
Falkland Islands & $58.45^{\circ} \mathrm{W}$ & $51.817^{\circ} \mathrm{S}$ & 3551 & RS80 \\
\hline
\end{tabular}

\section{Radiosonde data}

\subsection{Selection of launch stations}

The UK Met Office global radiosonde dataset consists of vertical profiles of pressure, temperature, relative humidity, specific humidity, wind speed and wind direction from the surface to a pressure level of approximately $10 \mathrm{hPa}$ from approximately 900 launch stations (UK Meteorological Office). These data are typically recorded at standard pressure levels of $1000,925,850,700,500,400,300,250,200,150,100$, $70,50,30,20$, and $10 \mathrm{hPa}$. Within this dataset a sub-set of ten radiosonde stations, sited predominantly around the UK but with three non-UK stations (Gibraltar, St. Helena and the Falkland Islands), have recorded vertical profiles at a higher vertical resolution, i.e. every two seconds. These profiles have been available from the 1990s onwards. In this paper, the high resolution radiosonde profiles for a five year period, from 1 January 2002 to 31 December 2006, from nine UK Met Office radiosonde launch stations as shown in Table 1, were used to study the vertical extent of ISS layers. Only nine of the ten available high resolution stations were used because the Aberporth sub-set is sparsely populated, with some months recording as few as six launches. Otherwise, for the nine stations used, launches were typically twice daily at local times of $1200 \mathrm{~h}$ and $2400 \mathrm{~h}$, although there were occasional variations in launch time by $\pm 2 \mathrm{~h}$. The only exception to this was St. Helena, which recorded approximately one launch per day, with approximately 20-25 launches per month.

\subsection{Relative humidity correction}

Vaisala Radiosonde instruments, particularly the RS80-H type, have been used globally for over 20 years and therefore a significant body of literature exists on the accuracy and limitations of these observations (Wang et al., 2002; Miloshevich et al., 2004; Vömel et al., 2007). The Vaisala 

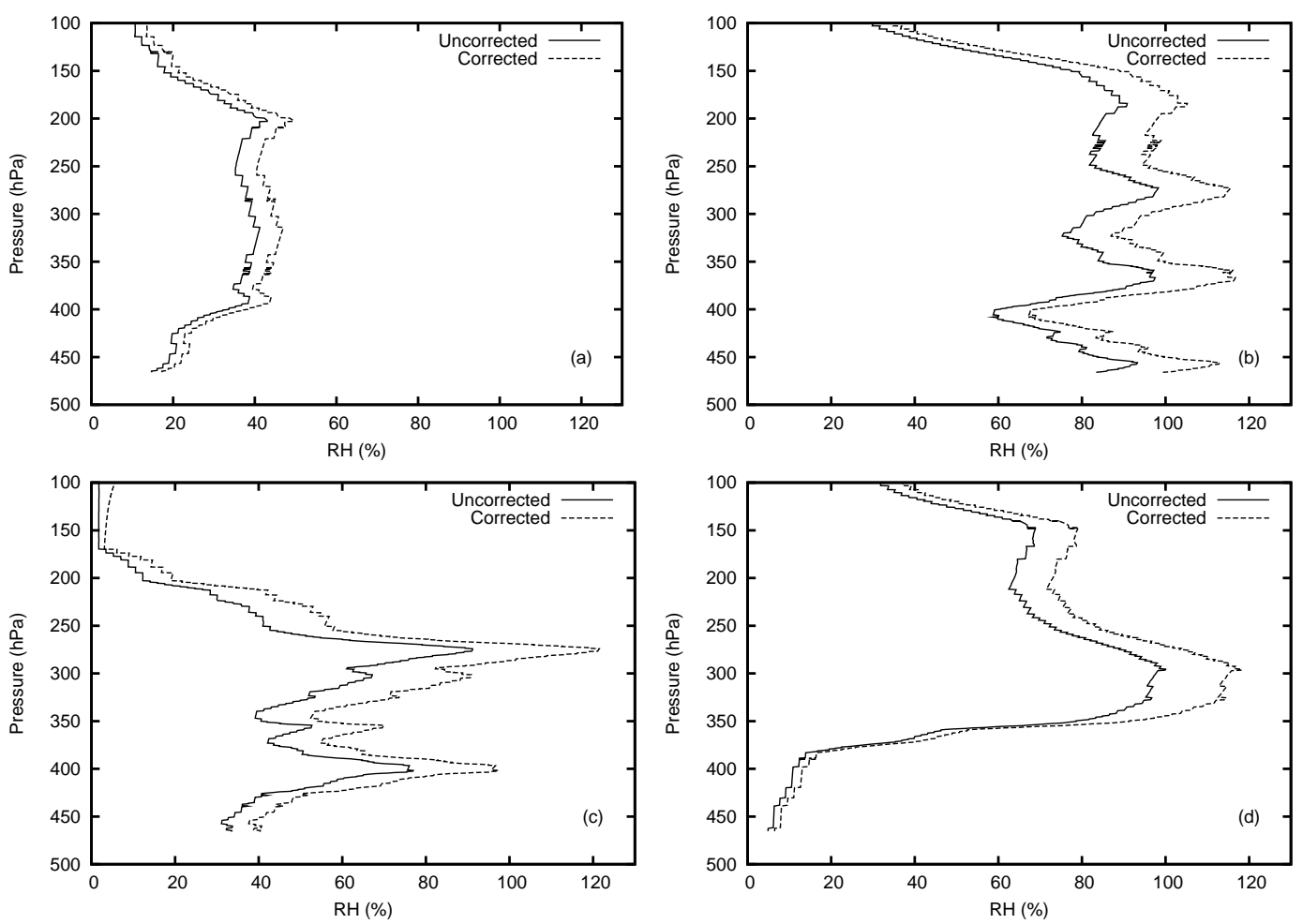

Fig. 1. A selection of example RHi profiles, corrected and uncorrected, from January 2004 from the Watnall high resolution radiosonde station using RS80-H radiosondes. These data are corrected for temperature dependency, chemical contamination and sensor ageing using the algorithm of Wang et al. (2002)

RS80-H radiosonde was in service with UK Met Office launch stations until approximately mid-2005, when the RS92 type radiosonde entered service. The exact changeover date was launch station dependent, but from the beginning of 2006 all observations used here were made with the RS92 radiosonde. Both RS80 and RS92 are subject to different systematic errors and as such these instruments have different correction algorithms. The RS80-H has specific issues over temperature dependency, chemical contamination, sensor ageing and measurement time lag, leading to a dry bias. To account for the resulting bias in observations, the correction presented by Wang et al. (2002) was used. RS92 observations are also subject to a dry bias, in this case due to the lack of a radiation shield, leading to solar heating of the humidity sensor (Vömel et al., 2007). There is less information regarding RS92 accuracy and only a few correction methods are available, however, a study by Vömel et al. (2007) was applied here to correct for the observation dry bias. Figure 1 shows uncorrected and corrected profiles for four arbitrarily chosen profiles using RS80-H radiosondes launched from the Watnall station $\left(1.25^{\circ} \mathrm{W}, 53.005^{\circ} \mathrm{N}\right)$ during January 2004. It is worthy of note, that in three of the four profiles, ISS events would not be observed if it were not for application of the correction algorithms (see also Rädel and Shine, 2007).
Whilst the example radiosonde ascents, shown in Fig. 1, provide an indication of the correction magnitude for individual ascents, the percentage corrections to the relative humidity are shown as functions of temperature for the RS80-H and RS92 radiosondes in Fig. 2. The average correction for the RS80-H is up to $\sim 20 \%$ at $212 \mathrm{~K}$ and for the RS92, during the daytime, the correction is between $\sim 15 \%$ at $273 \mathrm{~K}$ and $\sim 40 \%$ at $212 \mathrm{~K}$. This large correction for the RS92 is due to solar heating of the humidity sensor but for night-time observations, when there is no solar heating generated dry bias, the RS92 is corrected by up to $10 \%$ at $238 \mathrm{~K}$

The radiosonde time-lag correction (for both RS80 and RS92) is important in this study because it allowed for the recovery of small scale RH structures which may have been smoothed out due to the response rate of the radiosonde instruments (shown in Miloshevich et al., 2004). The time-lag error itself is a direct result of the humicap sensors non-zero response rate, which is the ability of the humicap to respond to changes in ambient humidity. Actually, the time-lag correction is applied to RH (and not separately to temperature or specific humidity) and is a function of temperature. The response rate of the temperature observations are not discussed directly in the published literature (Wang et al., 2002; Miloshevich et al., 2004; Vömel 


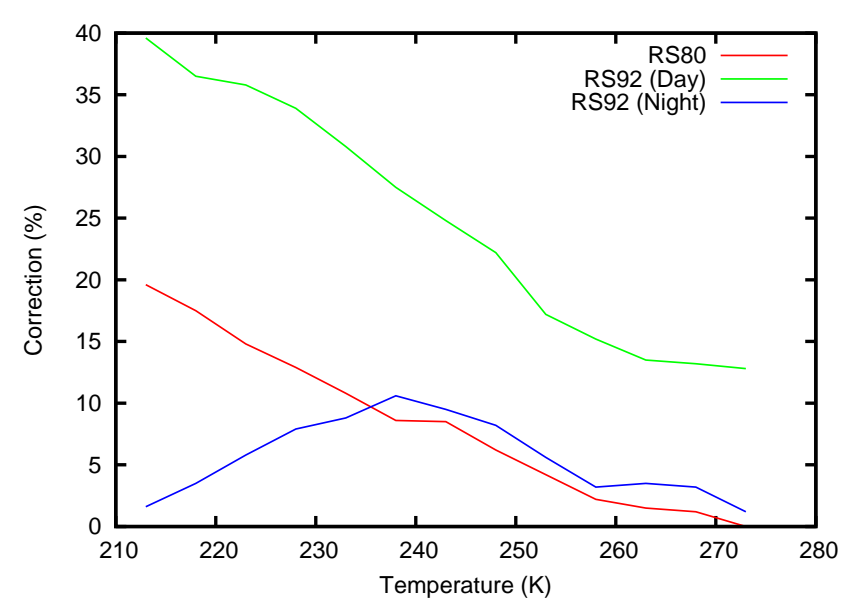

Fig. 2. The average correction made to the RS80-H and RS92 radiosonde relative humidity observations. In this case observations were corrected using Wang et al. (2002) for the RS80-H and Vömel et al. (2007) for the RS92.

et al., 2007). Therefore the explicit time-lag differences between observations of temperature and humidity are not considered in this paper. The time-lag correction cannot recover the structure associated with the resolution of the raw observations $(\sim 2 \mathrm{~s})$, instead the effective resolution of the observations used in this paper is $\sim 6 \mathrm{~s}$ in the troposphere (Wang et al., 2002; Miloshevich et al., 2004; Vömel et al., 2007).

An additional problem is that the RS80-H radiosondes are known to experience instrument sensor icing during some operations (Miloshevich et al., 2004). This could occur if the radiosonde passed through either super-cooled liquid water $\left(T<0^{\circ} \mathrm{C}\right)$ or an ice cloud. If this happened then ice formed on the sensor could remain even after the icing event, and as a result ice super-saturation could be measured for the remainder of the profile, even into the lowermost stratosphere (Miloshevich et al., 2004). To detect such erroneous events, all $\mathrm{RS} 80-\mathrm{H}$ radiosonde profiles which had $\mathrm{RH}>90 \%$ at high altitudes well into the lowermost stratosphere (the sensor icing criterion) were excluded from the analysis. To ensure that only anomalous data were excluded, the sensor icing criterion was applied to mid-latitude radiosonde profiles below a pressure threshold of $100 \mathrm{hPa}$. This altitude threshold is high enough (in mid-latitudes) to identify erroneous radiosonde profiles because mid-latitude tropopause altitudes have been shown to be at a mean altitude of $225-300 \mathrm{hPa}$ and with three-sigma standard deviations from this mean of around $100 \mathrm{hPa}$ (Hoinka, 1998b). In the tropics the tropopause altitude can be at pressures below $100 \mathrm{hPa}$ and, therefore, to mitigate the risk of removing genuine ISS events, the sensor icing criterion was not applied to any St. Helena radiosonde profiles. For all observations made with the RS92 instrument the application of the sensor icing criterion is unnecessary. This is because, in addition

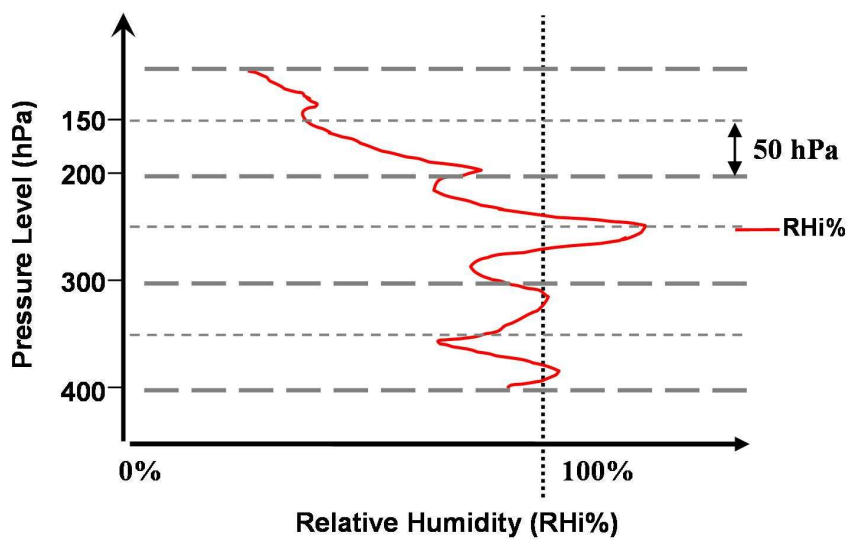

Fig. 3. A schematic diagram showing a high resolution RHi profile and how radiosonde RHi profiles were divided into $50-\mathrm{hPa}$ or $100-\mathrm{hPa}$ pressure layers. Each pressure layer could contain up to 100 high resolution RHi radiosonde observations.

to improved calibration accuracy and faster sensor response time, the RS92 eliminates sensor icing through alternately heated dual humidity sensors, which allows one sensor to be heated while the other makes the observation (Paukkunen, 1995).

An inevitable consequence of using radiosondes to observe the atmosphere is the impact of the horizontal advection on observations, and there is currently no readily available method to resolve this issue. In this paper the horizontal advection is not accounted for and actually it is not clear how much of an issue this is when understanding vertical profiles of the atmosphere. Importantly, the high-resolution radiosonde observations represent the closest (currently) in-situ representation of the atmospheres vertical profile.

\section{Analysis of radiosonde data}

Relative humidity with respect to ice (RHi), defined here as $U$, was calculated from the corrected relative humidity with respect to water $(\mathrm{RH})$ observations $\left(U_{\mathrm{w}}\right)$ using known water $\left(e_{\mathrm{w}}(T)\right)$ and ice $\left(e_{\mathrm{i}}(T)\right)$ saturation relationships (e.g. Goff and Gratch, 1946):

$U=\frac{e_{\mathrm{w}}(T)}{e_{\mathrm{i}}(T)} \cdot U_{\mathrm{w}}$.

This gave high resolution profiles of $\mathrm{RHi}$, which were divided either into five $50 \mathrm{hPa}(400-150 \mathrm{hPa})$ or two $100 \mathrm{hPa}$ pressure layers (400-200 hPa). An example high resolution profile, referenced to a $50 \mathrm{hPa}$ pressure layer discretization, is shown in Fig. 3.

Radiosonde observations of relative humidity have larger corrections around the tropopause and lower stratosphere, 
and the residual errors increase with altitude (Vömel et al., 2007). Therefore, to reduce uncertainties in the analysis, pressure layers which included the tropopause and higher were omitted. This was achieved by including only those pressure layers which maintained a negative lapse rate throughout that entire layer. As a result, the final analysis was based on 30462 radiosonde profiles which gave totals of 152310 50-hPa and 60924 100-hPa pressure layers.

\section{Probability of ice super-saturation occurrence}

Each pressure layer, whether $50 \mathrm{hPa}$ or $100 \mathrm{hPa}$, contained a high resolution RHi profile where each observation $U_{j}^{k}$ in a profile was defined by the RHi observed at point $j$ in pressure layer $k$. Here, as in Lamquin et al. (2009), a pressure layer average $\mathrm{RHi}\left(U^{k}\right)$ was calculated as

$U^{k}=\frac{\sum_{j} U_{j}^{k}}{N^{k}}$,

where $N^{k}$ is the number of profile RH measurements in that pressure layer.

Of course, the average RHi over an entire pressure layer is not expected to define the ISS fraction within that layer. To overcome this Lamquin et al. (2009) investigated whether ice super-saturation was observed at all (at least once) in a pressure layer. For example, a simple binary indicator $(I)$, where for each observation $I_{j}^{k}=1$ if $U_{j}^{k} \geq 100 \%$ and is zero otherwise is used. Then by letting $I^{k}=\max _{j} I_{j}^{k}$ means that $I^{k}$ will equal 1 when there is at least one ISS observation in a pressure layer $(k)$ and zero otherwise. This approach meant that while an ISS event in a pressure layer would be captured, the ISS fraction in that layer would not. In contrast, here a count of high resolution ISS events, where $I_{j}^{k}=1$, was made and an ISS fraction $\left(S^{k}\right)$ within a pressure layer was derived using the total number of observations in a pressure layer $\left(N^{k}\right)$, as:

$S^{k}=\frac{\sum_{j} I_{j}^{k}}{N^{k}}$.

For each pressure layer the ISS fraction $\left(S^{k}\right)$ was determined together with a layer average relative humidity $\left(U^{k}\right)$. Figure 4a shows the relationship between $S^{k}$ and $U^{k}$ for all 50-hPa pressure layers within the British Isles dataset, where each data point represents an individual pressure layer. Figure $4 \mathrm{~b}$ shows that these data are densely distributed around $U^{k}=100$, and that data points which are ice supersaturated are always greater than $U^{k}=40$. This contour plot indicates that there is some (possibly s-shaped) relationship between $\left(U^{k}\right)$ and $\left(S^{k}\right)$ and this is investigated further in the following sections.

Each pressure level data point, i.e. $\left(U^{k}, S^{k}\right)$, was grouped into average relative humidity bins $\left(U^{k}\right)$ to determine a probability relationship. To accomplish this, the pressure
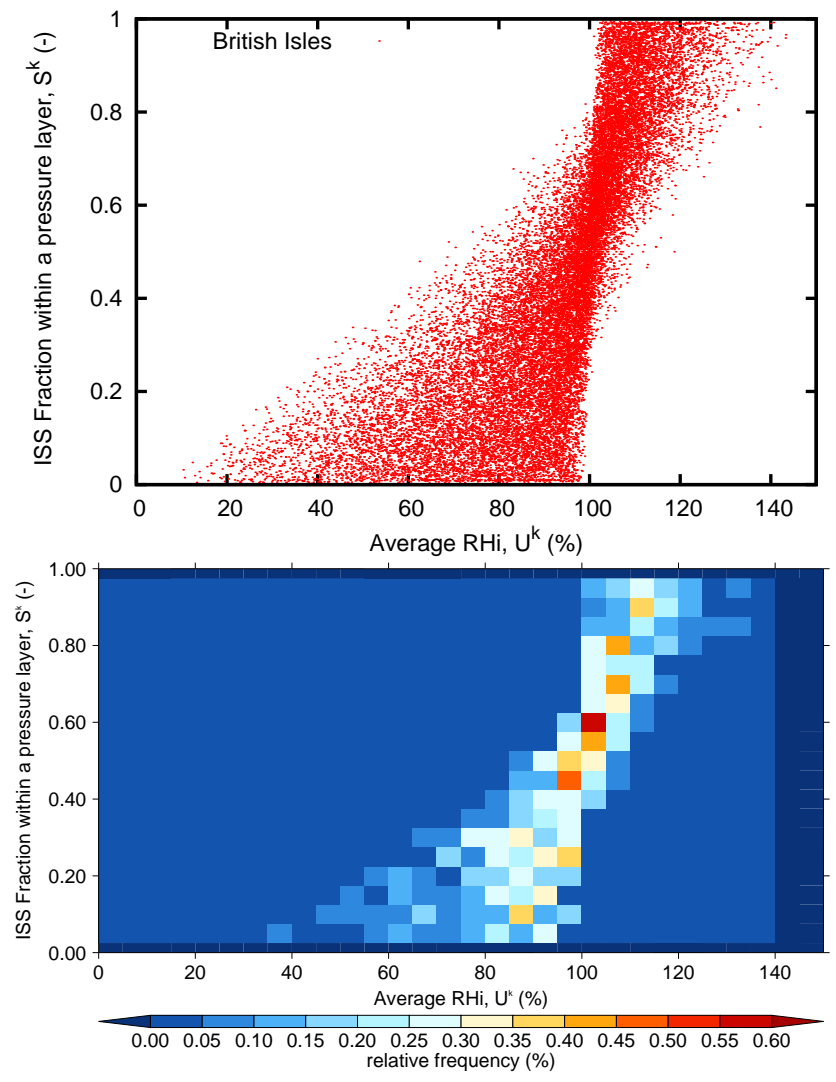

Fig. 4. Relationship between the average RHi $\left(U^{k}\right.$ in \%) and ISS fraction $\left(S^{k}\right)$ within $50 \mathrm{hPa}$ layers $(400-150 \mathrm{hPa})$. These data are derived from five years of UK Met Office high resolution radiosonde launches from Camborne, Castor Bay, Herstmonceux, Albemarle, Lerwick and Watnall launch stations (January 2002-December 2006). Panel (a) shows each individual $50 \mathrm{hPa}$ pressure layer from the full dataset. Panel (b) shows a contour plot of the probability distribution of the full dataset, for clarity (in the contour plot only) data from pressure layers of an ISS fraction $=0$ (zero ice supersaturation) and an ISS fraction $=1$ (fully ice supersaturated) were removed.

layer data were divided into 28 average relative humidity bins $(0 \%<u<140 \%$, in steps $\Delta u$ of $5 \% \mathrm{RHi})$, where $u$ represents the average relative humidity bin and $\Delta u$ is the bin size. Then by taking the mean of $S^{k}$ in each average relative humidity bin, the probability, $P(u \pm \Delta u / 2)$, of an ISS event occurring in any pressure layer with an average relative humidity bin, $u-\Delta u / 2$ to $u+\Delta u / 2$, was defined, that is:

$P(u \pm \Delta u / 2)=\frac{\sum_{k} S^{k}(u)}{n(u)}$,

where $n(u)$ is the number of pressure layers with $U^{k}$ within the average relative humidity bin $u \pm \Delta u / 2 . \quad P(u \pm \Delta u / 2)$ now represents the average ISS fraction in any pressure layer within an average relative humidity bin between $u=0 \%$ and $u=140 \%$. 

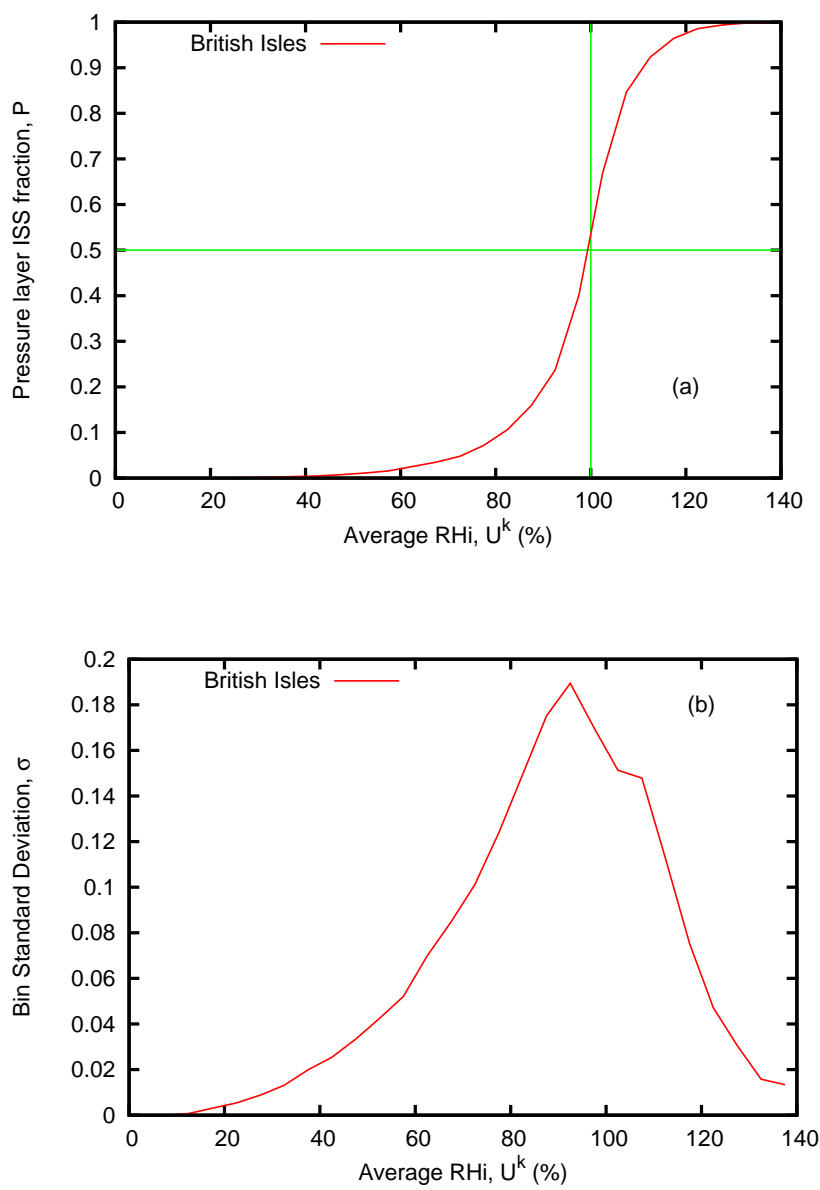

Fig. 5. Panel (a) shows the probability relationship between the average RHi and the ISS fraction, $P(u \pm \Delta u / 2)$, for $50-\mathrm{hPa}$ layers $(400-150 \mathrm{hPa})$. Panel (b) shows the standard deviation for the British Isles dataset from the s-shaped mean (in each relative humidity bin). The analysis was performed from five years of high resolution radiosonde launches from Camborne, Castor Bay, Herstmonceux, Albemarle, Lerwick and Watnall (January 2002-December 2006).

$P(u \pm \Delta u / 2)$ is equal to zero at $u=0 \%$ and equates to 1 when all observations in a pressure layer are ISS. This will occur at a minimum of $u=100 \%$ but layers with sub-saturated fractions can occur at $u>100 \%$. The relationship defined by Lamquin et al. (2009) is equal to zero at $u=0 \%$ but when $u=100 \%$, where there must be at least one ISS event, the relationship always equates to 1 (unity). Therefore, the Lamquin et al. (2009) relationship cannot represent sub-saturated events in layers which are ISS on average, and this limitation was the focus of the research here. By applying $P(u \pm \Delta u / 2)$ to the high resolution UK Met office radiosonde data an empirical description of the probability relationship between $U^{k}$ and $S^{k}$ was obtained. This probability relationship is described for the entire British Isles data-set by the s-shaped relationship shown in Fig. 5a, and at this stage the relationship does not account for variations in pressure level, geographical location, pressure layer depth or season. Empirically, the first occurrence of ice supersaturation is at an average RHi of $\sim 20 \%$, and therefore when the average RHi is below $20 \%$ the entire pressure layer is expected to be sub-saturated. Conversely, a 50-hPa pressure layer can have an average RHi as low as $20 \%$ and contain a non-zero ice supersaturation fractional occurrence. The probability of ISS events within a pressure layer increases towards an average RHi of $100 \%$, and at this point on the s-shaped curve the pressure layers are shown to contain an ISS fraction of approximately 0.5. From here the probability of more ISS observations within a pressure layer increases rapidly until the average RHi is greater than $130 \%$ where the pressure layer is entirely ISS. The standard deviation, of the British Isles dataset, from this s-shaped mean is shown in Fig. 5b. The standard deviation is low in the lower and higher average RHi bins, and highest in the middle bins, at around 90-95\% average RHi, where the standard deviation is up to an ISS fraction of \pm 0.18 within the bin. The s-shaped curve and standard deviation form the basis of an empirical and mathematical investigation.

\section{Empirical study of the s-shaped relationship}

\subsection{Interannual and geographical variation}

Differences in the s-shaped relationship, resulting from selecting sub-sets from the overall radiosonde dataset used here (e.g. by pressure level and location etc.), were investigated. Each s-shaped curve shown represents a specific data sub-set, and for ease of comparison the ISS fraction difference between the sub-set in question and the British Isles mean is also shown. Each time this ISS fraction difference will be compared to the standard deviation from British Isles s-shaped curve (shown in Fig. 5b) to demonstrate the statistical significance of the variables. Figure 6 shows all the data from the six British Isles launch stations, within $50-\mathrm{hPa}(250-300 \mathrm{hPa})$ pressure layers, for each individual calendar year. For each station and calendar year there is a clear s-shaped relationship, and while there is some variation between calendar years, the difference between the different curves and the British Isles mean is up to \pm 0.06 ISS fraction of a pressure layer, with maximum variability around $70-90 \%$ average RHi. The largest deviation from the British Isles average, which is observed consistently at all the stations, is for the 2006 sub-set and this is discussed further below.

To investigate the differences between geographic location further, and in the first instance just within the British Isles sub-set, for the pressure layer $250-300 \mathrm{hPa}$, the five calendar years of data per launch station were considered. Figure 7a shows the s-shaped relationship and Fig. 7b shows the difference in ISS fraction for each average RHi bin between the British Isles mean s-shaped curve and each 

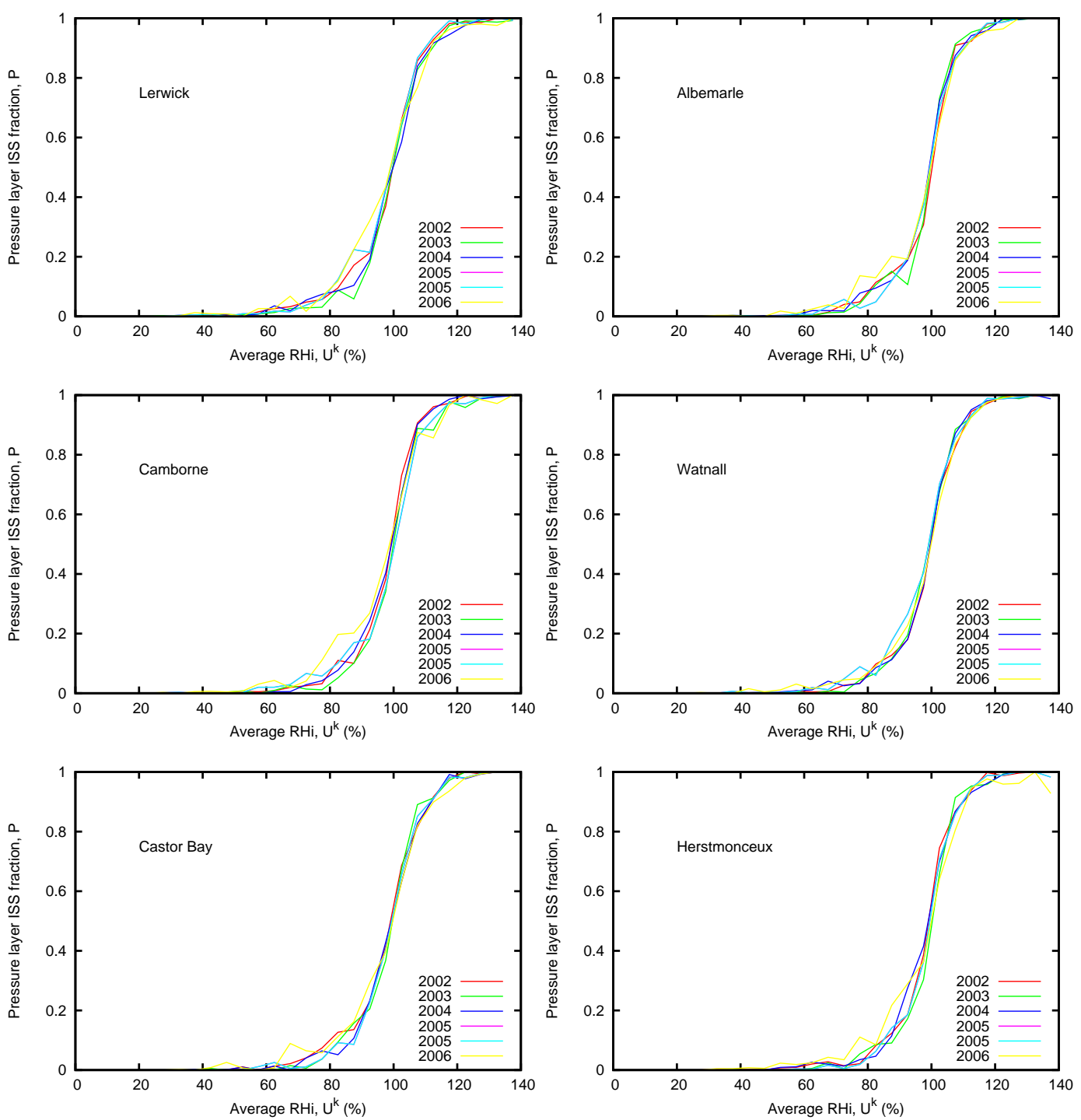

Fig. 6. The relationship between average RHi and the ISS fraction for the $250-300 \mathrm{hPa}$ pressure layer is shown. These curves are derived from individual calender years (January 2002-December 2006) of high resolution radiosonde launches from six launch stations within the British Isles.

launch station. Overall, a similar s-shaped relationship between the six stations is shown and this is likely to be due to the broadly consistent meteorological and topographical features between these stations. Global ISS event frequency and magnitude are expected to vary significantly between geographical locations (Gettelman et al., 2006a), and this would be expected to influence the s-shaped curve. However, within this British Isles dataset the selection of launch site only changes the curves shape by up to \pm 0.03 ISS fraction of a pressure layer, with the largest differences around $90-110 \%$ average RHi (see panel b).

Data from the same pressure layer was used to analyse the inter-annual variability between the calendar years 2002-2006, utilising all six British Isles launch stations, as shown in Fig. 8. The ISS fraction differences between the curves for each calendar year and the British Isles average are up to \pm 0.05 ISS fraction within a pressure layer and there are consistent s-shaped relationships, with similar absolute differences for the years 2002-2005. Interestingly, the 2006 curve shows smaller ISS fraction differences $( \pm 0.03)$ than the other calendar years but the curve has a different shape. In particular, average layers which are sub-saturated contain a higher fractional occurrence of ice super-saturation, and conversely, super-saturated layers show a lower fractional occurrence of ISS events. This difference could be due to the change in radiosonde instrument, from the RS80-H to the RS92, during mid-2005. While the exact changeover date is station dependent, the RS92 was 

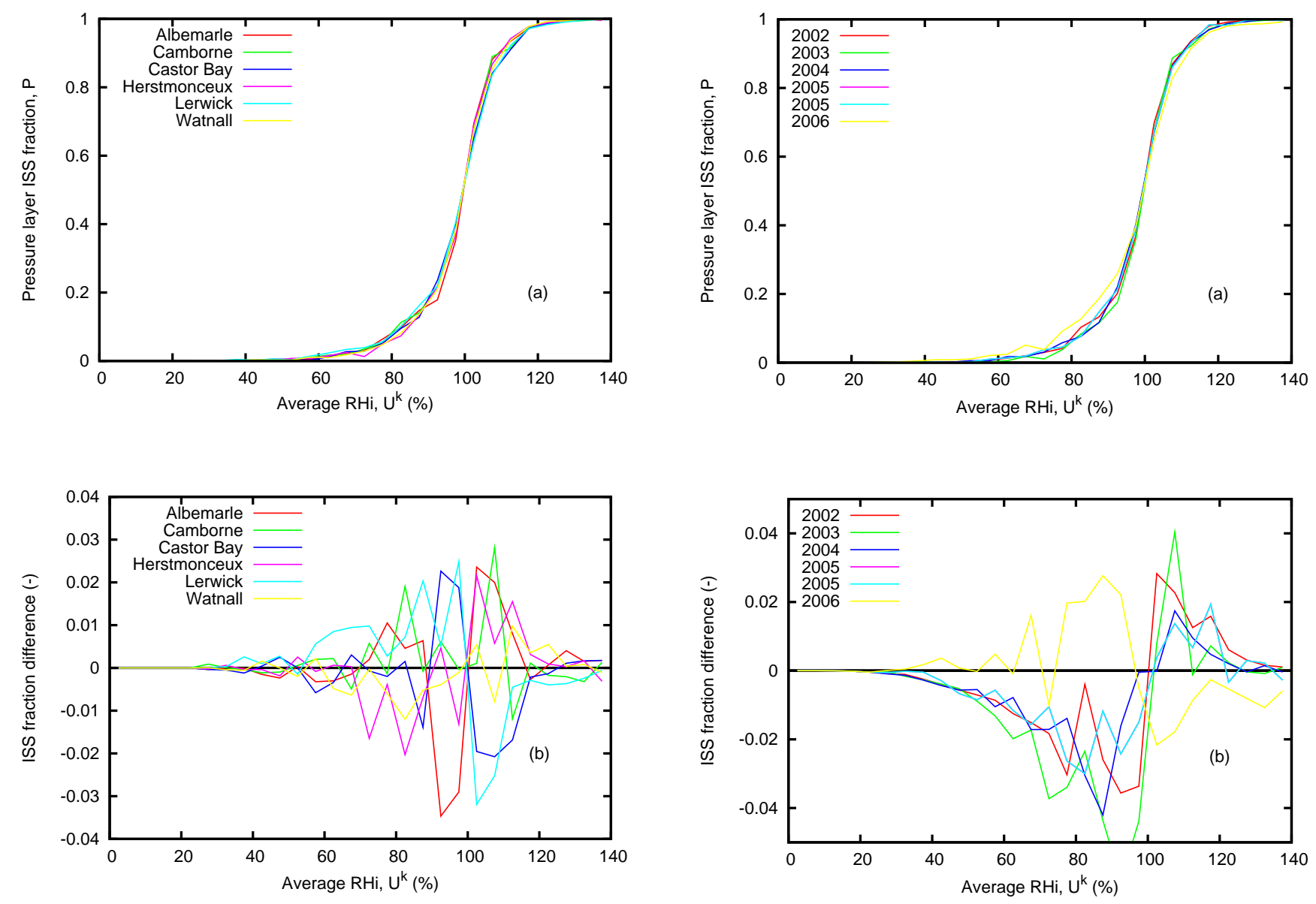

Fig. 7. The relationship between average RHi and the ISS fraction for the 250-300-hPa pressure layer is shown. Panel (a) shows the s-shaped relationships for each station and panel (b) shows the difference between curves from each station and the British Isles average s-shaped relationship. These data are from six high resolution radiosonde launch stations within the British Isles (January 2002-December 2006).

definitely in operation with all British Isles launch stations after 1 January 2006 (UK Meteorological Office). In comparison with the RS80-H, the RS92 offers improved calibration accuracy, faster response time and does not suffer from sensor icing (Paukkunen, 1995). A faster response time could lead to a more precise definition of an ISS layer when compared to the RS80-H, as the RS92 sensor can respond more quickly to changes between super-saturated and sub-saturated environments (Miloshevich et al., 2004). Therefore, using the RS92 could lead to the change in s-shaped curve demonstrated during the 2006 calendar year, but this is uncertain.

So far the analysis has focussed on 50-hPa pressure layers from the British Isles dataset, and has considered the impact of inter-annual variability and geographical location on the form of the s-shaped curve. The largest differences in the s-shaped curve, of up to \pm 0.06 ISS fraction within a pressure

Fig. 8. The relationship between average RHi and the ISS fraction for the 250-300 hPa pressure layer is shown. Panel (a) shows the s-shaped relationships and panel (b) shows the difference between each calender year curve and the British Isles mean. These data are from six high resolution radiosonde launch stations within the British Isles (January 2002-December 2006).

layer, are observed between the average RHi bins of $70 \%$ and $110 \%$. Importantly, within this same set of average RHi bins the standard deviation from the British Isles dataset is between \pm 0.08 and \pm 0.18 , respectively. Therefore, given that the maximum s-shaped curve deviation from the British Isles mean is smaller than the standard deviation for the dataset, the single s-shaped curve, shown earlier in Fig. 5a, is likely to be representative of this region, irrespective of geographical and inter-annual variability. Given this, for all further analysis the British Isles mean s-shaped curve will be used as the datum for comparison.

\subsection{Altitude variation and vertical resolution}

The next stage was to conduct a comparison between different pressure levels $(150-400 \mathrm{hPa})$ and layer depths $(50$ and $100 \mathrm{hPa}$ ), and these are shown in Fig. 9. For 50-hPa pressure layers the variation in pressure level change, 

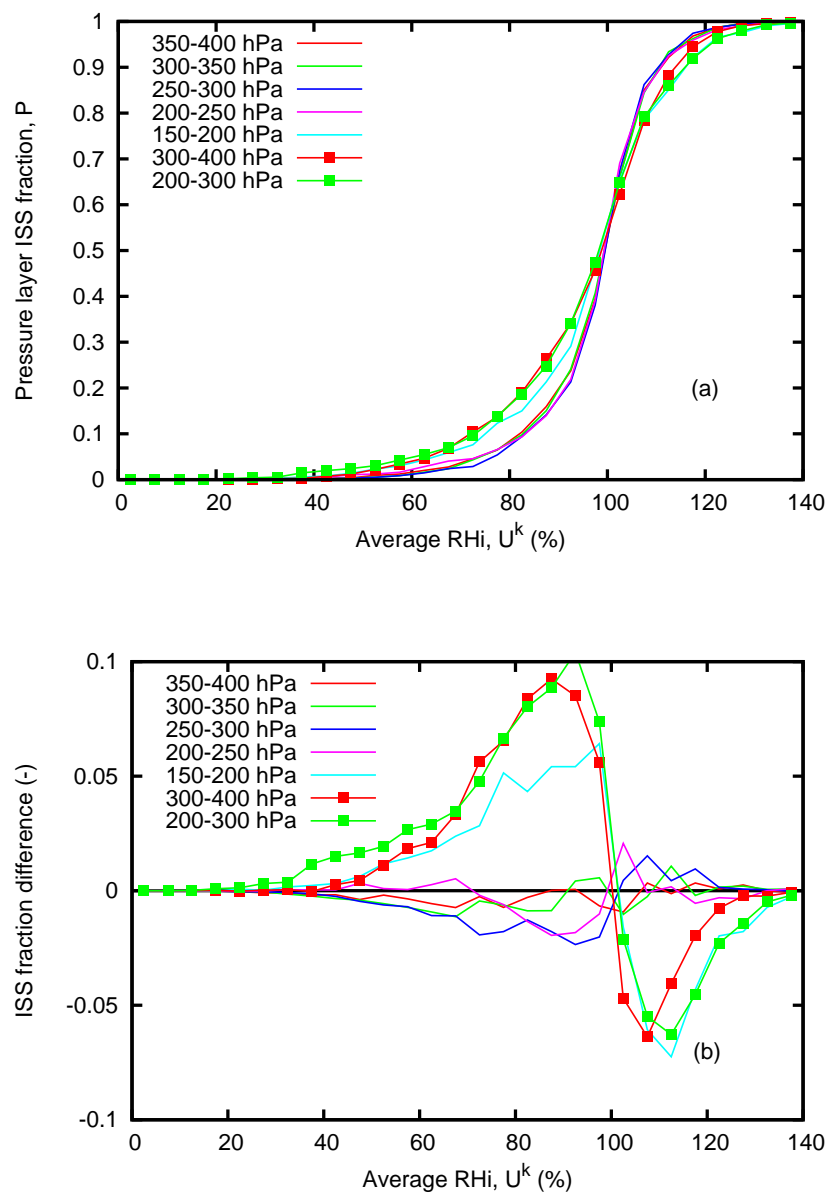

Fig. 9. The relationship between average RHi and the ISS fraction within individual $50 \mathrm{hPa}$ and $100 \mathrm{hPa}$ pressure layers is shown in panel (a). The differences between them are shown in panel (b). These data are derived from six high resolution radiosonde launch stations within the British Isles (January 2002-December 2006).

in the first instance between 200 and $400 \mathrm{hPa}$, means that the s-shaped curve changes by up to \pm 0.02 ISS fraction. At the lower pressure level of $150-200 \mathrm{hPa}$ the curve changes shape (Fig. 9a) and differences in ISS fraction of up to \pm 0.07 ISS fraction are observed (Fig. 9b). The proximity of this pressure layer $(150-200 \mathrm{hPa})$ to the tropopause could influence the shape of the curve, as the atmosphere in this region is typically colder and drier than at higher pressure levels (e.g. Gierens et al., 1999; Houghton, 2002; Spichtinger et al., 2002, 2003a). While the impact of including the tropopause within any given pressure layer is removed, as discussed earlier, the lower occurrence of fully super-saturated layers shown by the s-shaped curve (Fig. 9a) at this pressure level is likely to be related to the higher prevalence of drier air masses near the tropopause. Specifically, Hoinka (1998a) presented a 15-year (1979-1993) relative humidity global mean for the tropopause, where relative humidity is approximately $10 \%$ in mid-latitudes. When pressure layer depth is varied, between 50 and $100 \mathrm{hPa}$, a more significant change in the s-shape is observed. Figure $9 \mathrm{~b}$ shows that, as the pressure layer depth is increased, the probability of capturing more ISS events in on average sub-saturated layer increases and consequently the probability reduces in on average super-saturated layers. Furthermore, Fig. 9b shows that the ISS fraction differences for 100-hPa s-shaped curves are larger for average sub-saturated layers (up to \pm 0.1 ) when compared to average super-saturated layers (up to \pm 0.06 ). Overall, the difference between 100-hPa s-shaped relationships and the British Isles mean is up to \pm 0.1 ISS fraction of a pressure layer. Therefore, vertical resolution is an important variable when applying any s-shaped function to vertical thick pressure layers, and will be considered in all further analysis.

An s-shaped relationship is applicable to both $50-\mathrm{hPa}$ and $100-\mathrm{hPa}$ thick pressure layers at all pressure levels between $400 \mathrm{hPa}$ and $150 \mathrm{hPa}$. Specifically, for $50-\mathrm{hPa}$ pressure layers at levels up to $200 \mathrm{hPa}$ the British Isles mean s-shaped curve is representative. The changing shape of the curve between $150-200 \mathrm{hPa}$ (up to \pm 0.06 ISS fraction) also can be represented by the dataset mean because the difference between ISS fraction in all average RHi bins is within the standard deviation of the British Isles dataset. The ISS fraction difference between the British Isles mean and both $100-\mathrm{hPa}$ layers $(200-300 \mathrm{hPa}$ and $300-400 \mathrm{hPa})$ is also consistently within the standard deviation of the dataset. Therefore, when representing $100-\mathrm{hPa}$ pressure layers the British Isles mean (for 50-hPa pressure layers) is arguably still applicable. However, the 100-hPa layer curve is shallower than the $50-\mathrm{hPa}$ curve and the deviation from the British Isle mean is significantly larger than the deviation shown by other variables analysed. The pressure layer depth is also the variable of most interest particularly if any mathematical model based on these s-shaped curves is to be applied to data of different pressure layer depths. Therefore the conclusion here is that a different s-shape is required for different pressure layer depths. The variation in the s-shape demonstrated between $50-\mathrm{hPa}$ and $100-\mathrm{hPa}$ layers will be considered further during the development of a mathematical model later in this paper.

\subsection{Seasonal variation}

Rädel and Shine (2007) showed (using standard resolution radiosonde data) that during the winter $15-25 \%$ of $\mathrm{RHi}$ observations showed ice supersaturation and during the summer $5-15 \%$ of RHi observations were ice supersaturated. Given this, it is expected that the s-shaped curve will be influenced by season. Again the British Isles dataset was used, but this time only $50 \mathrm{hPa}$ pressure layers between 200-400 hPa were considered, so any uncertainties over pressure layer depth and level were removed. Figure 10 shows that the largest ISS fraction differences are between 

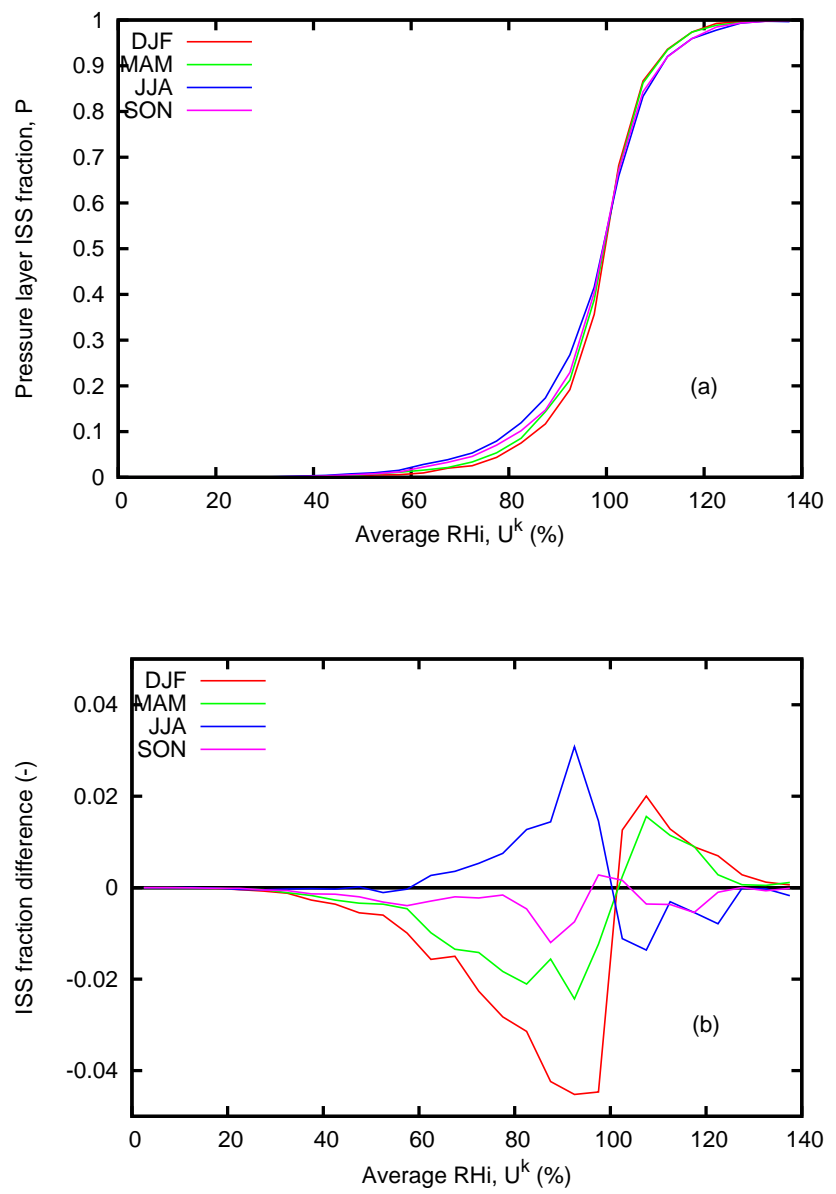

Fig. 10. The relationship between average RHi and the ISS fraction within $50-\mathrm{hPa}$ pressure layers, comparing individual seasons is shown in panel (a). The differences between them and the British Isles average curve are shown in panel (b). These data are derived from six high resolution radiosonde launch stations within the British Isles (January 2002-December 2006).

the summer and winter curves, and this reflects the higher occurrence of ISS events observed during winter months when compared to the summer. The ISS fraction differences are within $\pm 0.04-0.05$ of the British Isles average, with the largest variation in average RHi bins between 85 and $100 \%$ during winter months.

\subsection{Gibraltar, St. Helena and Falkland Islands}

This paper has so far concentrated on launch stations within the British Isles, and therefore the next the step is to include those Met Office launch stations, at different latitudes, from Gibraltar, St. Helena and the Falkland Islands. Figure 11 shows the s-shaped relationship for Gibraltar and the Falkland Islands which show ISS fraction differences of up to \pm 0.03 from the British Isles mean. These two stations have shown similar frequencies of ISS event occurrence to the British Isles during winter and summer months, i.e. more
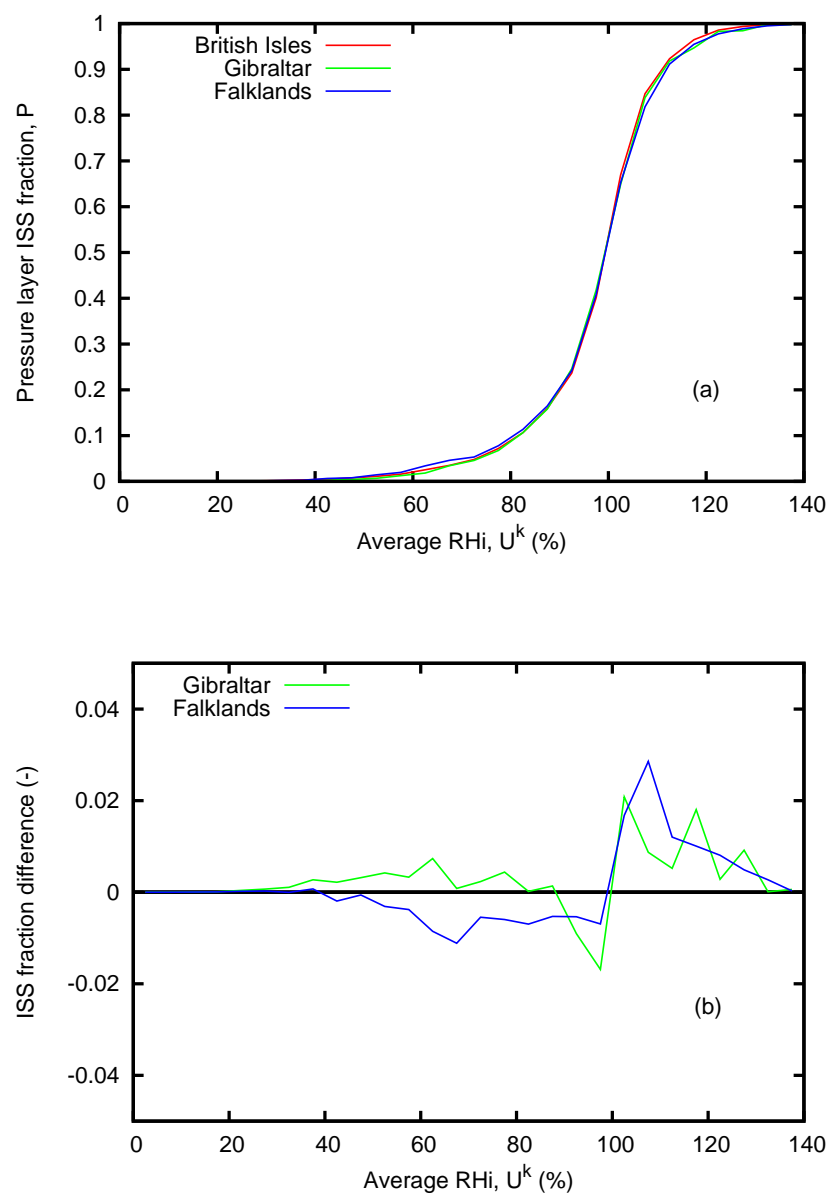

Fig. 11. The relationship between average RHi and the ISS fraction within 50-hPa pressure layers, comparing Gibraltar and the Falkland Islands to the Bristish Isles mean is shown in panel (a). The differences between them and the British Isles average curve are shown in panel (b). These data are derived from six high resolution radiosonde launch stations within the British Isles and one from both Gibraltar and the Falkland Islands (January 2002-December 2006).

ISS events during the winter (10-25\%) and less during the summer (5-15\%) (Dickson et al., 2010). Therefore, the s-shaped curves are similar to the British Isles mean and the ISS fraction differences are well within the standard deviation of the British Isles dataset. Given this, the single British Isles s-shape curve could be used to represent both these mid-latitude locations.

The data from St. Helena is shown in a different manner, in Fig. 12, because the occurrence of ISS events is much lower than for the other eight launch stations. In fact, Dickson et al. (2010), using the same five year (2002-2006) St. Helena dataset showed that ISS events are only observed on average $\sim 2.1 \%$ of the time, compared to $5-25 \%$ for mid-latitude locations. This means that the number of pressure layers containing any amount of ice super-saturation 


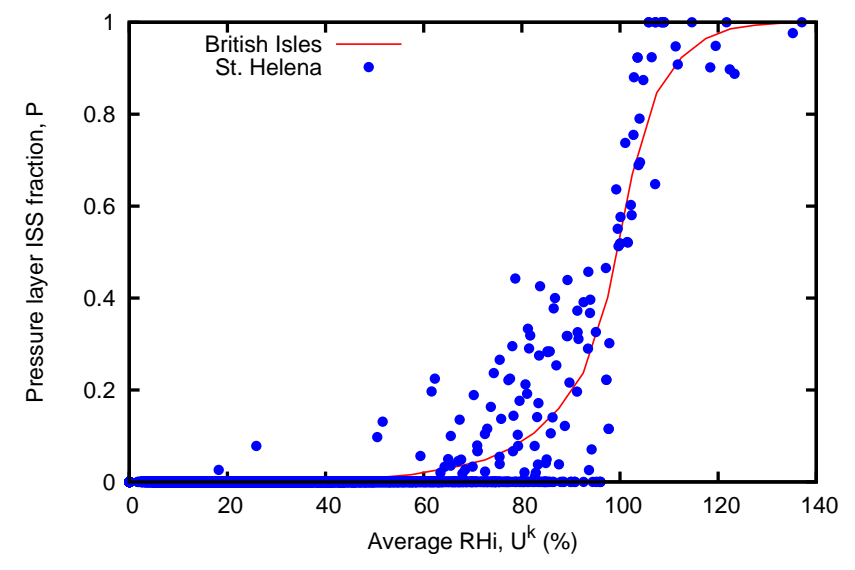

Fig. 12. The relationship between average RHi and the ISS fraction within $50 \mathrm{hPa}$ pressure layers, comparing data from St. Helena to the British Isles mean is shown. The s-shaped relationship for St. Helena is not shown because the ISS fraction is too low $(\sim 2.1 \%)$. These data are derived from six high resolution radiosonde launch stations within the British Isles and one from St. Helena (January 2002-December 2006).

is too small to generate a coherent curve. This is the only station within this sub-set which is located in the tropics and, as discussed earlier, because the tropopause is typically at a lower pressure, this launch station data sub-set has two more $50 \mathrm{hPa}$ pressure layers between $150 \mathrm{hPa}$ and $50 \mathrm{hPa}$ compared to all other stations. Even with this larger pressure range, the fractional occurrence of ice super-saturation observed at mid-latitude locations (5-25\%) is not observed at St. Helena. Therefore, there is a lower occurrence of ISS events at St. Helena and satellite studies of global ice supersaturation distribution do support the lower occurrence of ISS events in the tropics $(\sim 10 \%)$, particularly when compared to the frequency of ISS events in the extra-tropics (up to 40\%) (Gettelman et al., 2006a). This does not mean that an s-shaped curve is not applicable to St. Helena, or for that matter the tropics $\left(23.4^{\circ} \mathrm{N}-23.4^{\circ} \mathrm{S}\right)$, but that this St. Helena dataset does not demonstrate the curve. Furthermore, approximately $98 \%$ of the St. Helena pressure layers are within the standard deviation of the British Isles dataset (up to \pm 0.18 ISS fraction difference in a pressure layer), and therefore the s-shape for the British Isles dataset could be representative of the St. Helena station. The findings from this tropical analysis should be treated with caution because St. Helena has no clear counterexample, and in order to confirm these findings further analysis using other tropical radiosonde datasets is recommended.

To conclude, empirically the s-shaped curve, for $50-\mathrm{hPa}$ pressure layers between 150 and $400 \mathrm{hPa}$, appears to be representative of ISS events within thick pressure layers in the British Isles. This curve is also valid for the other mid-latitude locations of Gibraltar and the Falkland Islands. The tropical station of St. Helena has a low occurrence of ice super-saturation $(\sim 2.1 \%)$ and therefore constructing an s-shape, even with five years of data, was not possible. However, similar trends to the British Isles dataset are evident wherever ISS events occur in pressure layers, and specifically most of the St. Helena pressure layers are within the standard deviation of the British Isles dataset. This means that the s-shaped curve could be representative of the St. Helena station, and the tropics, but a specific study, with a larger more geographically varied dataset, is recommended. Other variables such as, pressure level, inter annual variation and seasonality do influence the s-shape curve but, as presented, variations from the British Isles mean are within the standard deviation of the dataset. Therefore, for these variables a single s-shaped curve is representative. The only variable of importance to the formation of the s-shape, as described earlier, because of its statistical significance and importance in application to low resolution data, is pressure layer depth. Therefore this variable will be considered during the next stage, which is to develop a mathematical model of the s-shape.

\section{Mathematical model of the s-shaped relationship}

In this section a simple mathematical model to represent the s-shaped curve is presented. The findings from the empirical investigation showed that a single s-shape, i.e. the s-shape from the British Isles, is valid for $50-\mathrm{hPa}$ pressure layers between $150-400 \mathrm{hPa}$, for stations outside the British Isles (Gibraltar, the Falkland Islands and St. Helena) and for both summer and winter seasons. Moreover, given that the only statistically significant variable, as found earlier, is the pressure layer depth, then this modelling exercise is focussed upon developing a mathematical relationship for the British Isles dataset and for both 50- and 100-hPa pressure layer depths.

In Sect. 4 it was stated that each pressure layer contained a high resolution RHi profile, where each observation, $U_{j}^{k}$, in a profile was defined by the RHi observed at point $j$ in pressure layer $k$. Earlier using this definition the ISS fraction $\left(S^{k}\right)$ in a thick pressure layer and the average relative humidity $\left(U^{k}\right)$ over the same layer were calculated. Here the mathematical modelling exercise begins by again calculating $U^{k}$ for each pressure layer for the full British Isles dataset. However, this time, instead of calculating $S^{k}$, the cumulative probability distribution of all $U_{j}^{k}$ observations in thick pressure layers, grouped by $U^{k}$ into bins of $u-\Delta u / 2$ to $u+\Delta u / 2$, was calculated. Again $u$ represented the average relative humidity bin, $\Delta u$ is the bin size, and the pressure layer data were divided into 28 average relative humidity bins $(0 \%<u<140 \%$, in steps $\Delta u$ of $5 \%$ RHi). The cumulative distribution of each bin grouping is $F_{u}(x)$, i.e. this represents the probability of finding a particular RHi value $(U)$ which is less than $x$ in any of the layers $k$ that had $U^{k}$ within $u \pm \Delta u / 2$. 


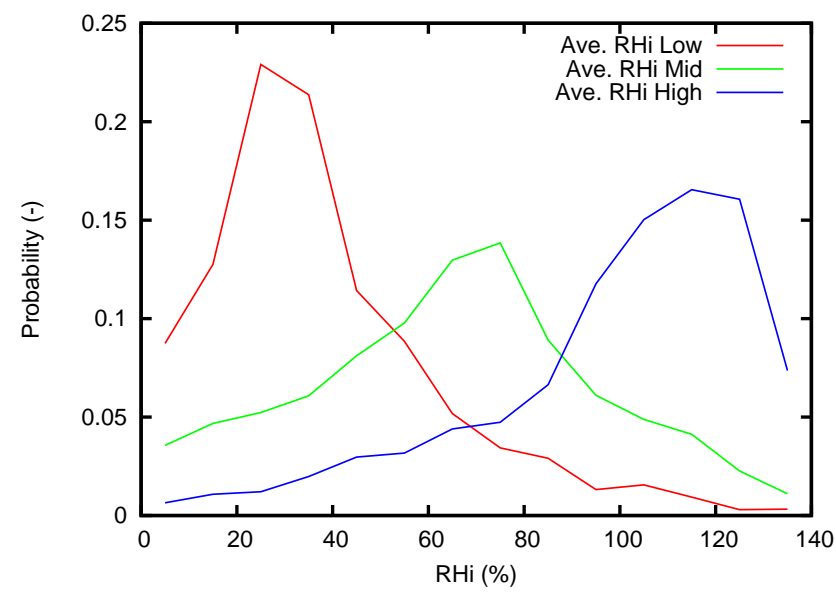

Fig. 13. Probability densitiy functions of RHi distributions in thick pressure levels and three average relative humidity bins. A low bin (average RHi 15-20\%, red line), mid-bin (55-60\%, green line), and a high bin (115-120\%, blue line). The distributions are derived from the British Isles dataset (January 2002-December 2006).

Therefore, the probability of finding an ISS event in any thick pressure layer, i.e. when $x=100$, is

$1-F_{u}(100):=\overline{F_{u}}(100) \equiv P(u \pm \Delta u / 2)$

which is equivalent to the probability of having a certain ISS fraction in layers with average RHi in the interval $u \pm \Delta u / 2$.

To construct a mathematical model in this way the distributions of $U_{j}^{k}$ in each average relative humidity bin needs to be quantified. Therefore, by way of example, three average relative humidity bins are chosen 15-20\% (low-bin), 55-60\% (mid-bin), 115-120\% (high-bin) and Fig. 13 shows the distribution of $U_{j}^{k}$ in each bin. The probability distributions of $U_{j}^{k}$ in each average relative humidity bin are mono-modal, right skewed in the low-bin, left skewed in the high-bin and approximately symmetrical (normal) in the mid-bin. These distributions are similar to those derived from airborne data in the upper troposphere (Gierens et al., 2007).

A Gaussian distribution is certainly applicable for the mid-bin (15-20\%) and this is representative of bins between $40 \%$ and $80 \%$ average relative humidity. For the low-bin (representative of bins $<40 \%$ average $\mathrm{RHi}$ ) and upper bin (representative of bins $>80 \%$ average RHi), including those which are ice super-saturated on average, the Gaussian distribution is not fully representative, and in particular does not account for the skewness or the tails of the high and low RHi distributions. However, the mono-modal characteristic, of both the high and low average relative humidity bin distributions, is captured and for the purposes of mathematical modelling here a Gaussian distribution is used to represent all average relative humidity bins. Each bin therefore is assumed to have a Gaussian distribution,

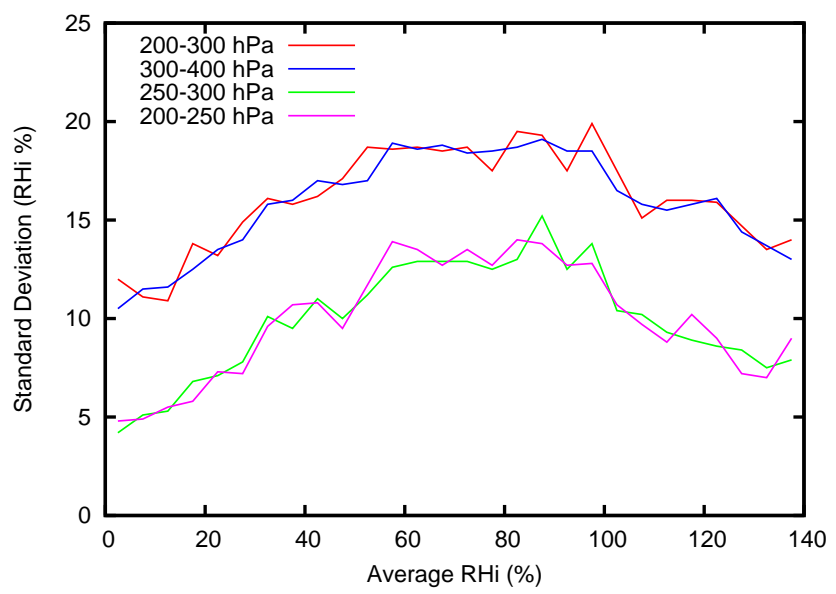

Fig. 14. Standard deviations $\left(\sigma_{u}\right)$ versus average RHi (bin-wise) in 50- and 100-hPa pressure layers. The data are derived from the British Isles dataset (January 2002-December 2006).

with a mean RHi (which is the same as the $u$ for that bin) and a corresponding standard deviation $\left(\sigma_{u}\right)$. Using these data for each average relative humidity bin, a further mathematical formulation of (as defined in Eq. 5), or the probability of finding an ISS event in any arbitrary average relative humidity thick pressure layer, can be constructed. Equation (6) shows how $\overline{F_{u}}(100)$ is modelled using the integral of a Gaussian distribution, or an error function:

$\overline{F_{u}}(100) \approx \frac{1}{2}-\frac{1}{2} \operatorname{erf}\left[\frac{100-u}{\sqrt{2} \sigma_{u}}\right]$.

To utilise this error function based formulation of $\overline{F_{u}}(100)$ an understanding of the standard deviation for each average relative humidity bin, $u \pm \Delta u / 2$, is required. As stated earlier this mathematical model focuses on the representation of the British Isle s-shaped curves for both $100-\mathrm{hPa}$ and $50-\mathrm{hPa}$ pressure layers. The standard deviation in each of the 28 bins is shown in Fig. 14 for pressure layers $200-300 \mathrm{hPa}$, $300-400 \mathrm{hPa}, 200-250 \mathrm{hPa}$, and $250-300 \mathrm{hPa}$. The four standard deviation datasets show similar trends with the largest $\sigma_{u}$ in the mid-bins and lower $\sigma_{u}$ in high- and low-bins. The $\sigma_{u}$ in any $50-\mathrm{hPa}$ layer is smaller than that of any $100-\mathrm{hPa}$ layer. This is due to the thicker 100 -hPa layer having a larger $U_{j}^{k}$ variance, because approximately twice as much data is captured compared to the $50-\mathrm{hPa}$ layer, and therefore the probability of a larger variance, and so $\sigma_{u}$, increases.

The British Isles data is now represented by average relative humidity bins, $u \pm \Delta u / 2$, and in each bin, a standard deviation of RHi observations, $\sigma_{u}$. These data, $\left(u, \sigma_{u}\right)$, from the four thick pressure layers considered here, are used with the mathematical error function model and an s-shaped description of ISS events, for thick pressure layers, represented by average relative humidity, is constructed, as 

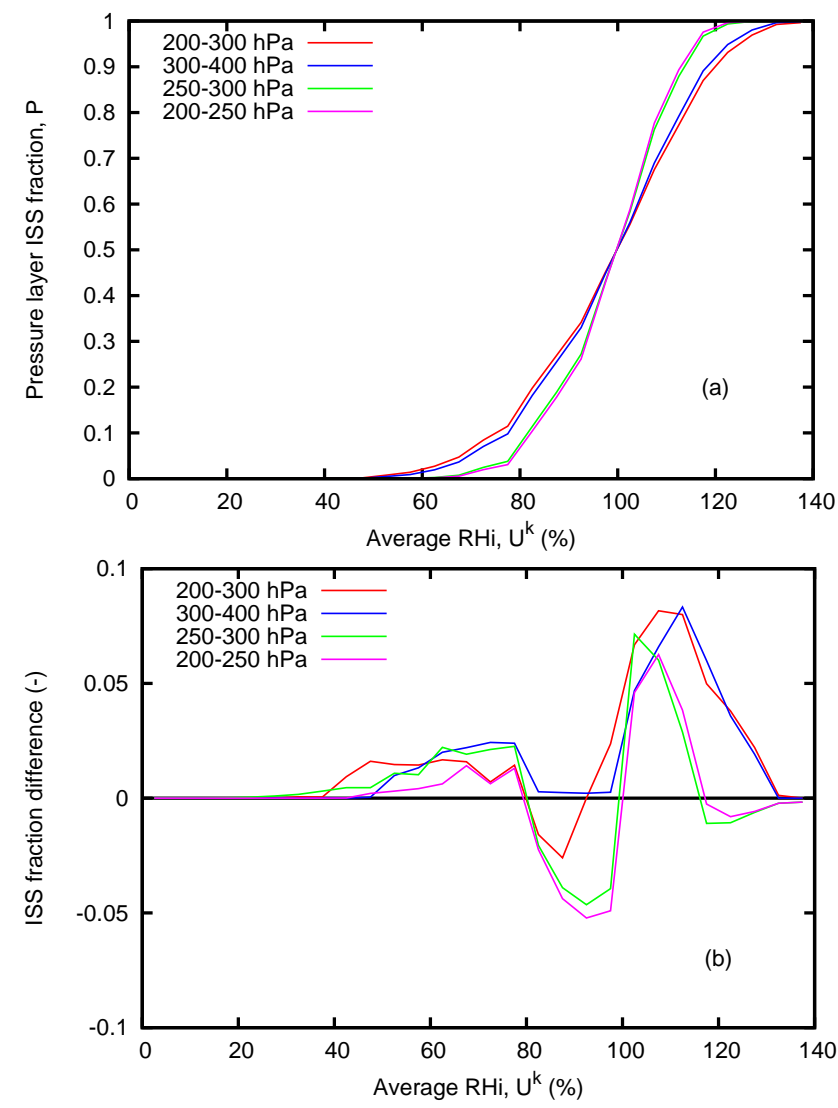

Fig. 15. S-shaped curves constructed using an error function representation for $\overline{F_{u}}(100)$ with the standard deviations from Fig. 14 are shown in panel (a) for two 50- and two 100-hPa pressure layers. Panel (b) displays the differences between the modelled curves and the average derived from the British Isles dataset (January 2002-December 2006).

shown in Fig. 15a. The differences in ISS fraction between the modelled s-shape curves and the curves generated from observations (shown earlier in Fig. 9) is shown in Fig. 15b. The differences here are between -0.05 and 0.08 ISS fraction. If the same rationale is employed here as in Sect. 5, in that the ISS fraction differences are compared to the British Isles dataset ISS fraction standard deviation ( \pm 0.18 ISS fraction) shown earlier in Fig. 5b, then the differences between observation generated s-shaped curves and modelled s-shapes are within acceptable limits. Of course the modelled s-shaped curves rely on $\sigma_{u}$ and these data are produced from observations. However, it is proposed that the $\left(u, \sigma_{u}\right)$ dataset for the British Isles, for both $50-\mathrm{hPa}$ and $100-\mathrm{hPa}$ pressure layers, can be used with the error function model for other geographical locations, pressure levels (400-150 hPa), seasons and years. Finally, this model can be used, to represent ISS events, in modelled data where only low vertical resolution is available. This will be useful in understanding the global distribution of ice super-saturation and modelling persistence of contrails.

\section{Concluding remarks}

Five years, from January 2002 to December 2006, of corrected high resolution radiosonde profiles, from nine UK Met Office launch stations, were used to investigate the fractional occurrence of ice super-saturation within $50-\mathrm{hPa}$ and $100-\mathrm{hPa}$ thick vertical pressure layers. The nine launch stations consisted of six within the British Isles and one from each of the Falkland Islands, Gibraltar and St. Helena. The analysis was based on 30462 radiosonde profiles which gave totals of 15231050 -hPa and 60924 100-hPa pressure layers. Within each pressure layer the average RHi and ISS fraction of the same pressure layer were derived and this allowed for the development of an empirical s-shaped relationship which linked the ISS fraction to the average RHi in any $50-\mathrm{hPa}$ or $100-\mathrm{hPa}$ pressure layer. The analysis was extended to identify the statistical significance of variations between s-shaped curves for geographical location of launch station, seasonality, pressure level and pressure layer depth. In each case the British Isles average s-shaped curve (i.e. 5 years, 50-hPa layers and six launch stations) was used as a datum to assess the influence of each variable on the s-shaped curve.

Within the British Isles, launch stations displayed similar s-shaped relationships and were within \pm 0.03 ISS fraction difference in a pressure layer of one another. Seasonality in mid-latitudes also impacts the s-shaped relationship, by between 0.04 and 0.05 ISS fraction from the British Isles mean, and with higher occurrences of derived ISS fractions during the winter compared to the summer. Increasing the pressure layer depth from $50 \mathrm{hPa}$ to $100 \mathrm{hPa}$ also shows deviations from the mean British Isles s-shaped relationship but by up to \pm 0.1 ISS fraction. Pressure level changes $(150-400 \mathrm{hPa})$ show $\pm 0.03-0.07$ ISS fraction differences within a pressure layer for $50-\mathrm{hPa}$ pressure layers. Inter-annual variability, for calendar years between 2002 and 2006, showed deviation from the mean of up to \pm 0.06 ISS fraction. Stations outside the British Isles, and in the first instance, Gibraltar and Falkland Islands stations, both representative of mid-latitudes, show ISS fraction differences of \pm 0.03 from the British Isles mean s-shape curve. Interestingly, at the tropical station of St. Helena, an s-shaped curve was not formed and this was due to the lower occurrence of ISS events observed at this station $(\sim 2.1 \%$ of observations were ISS). This lower occurrence of ISS events in the tropics is supported by satellite observation (Gettelman et al., 2006a). This does not mean that an s-shaped curve is not applicable to St. Helena, or for that matter the Tropics $\left(23.4^{\circ} \mathrm{N}-23.4^{\circ} \mathrm{S}\right)$, but that this St. Helena dataset does not demonstrate the curve. Furthermore, approximately $98 \%$ of the St Helena pressure layers are within the standard deviation of the British Isles dataset (up to \pm 0.18 ISS fraction difference in a pressure layer), and therefore the s-shape for the British Isles dataset could be representative of the St. Helena station. The empirical form of the s-shaped function has been demonstrated for 
mid-latitude locations and has shown sensitivity to changes in geographical location, season, pressure level and pressure layer depth of up to \pm 0.1 ISS fraction difference in any thick pressure layer. However, given that the standard deviation of the British Isles dataset (the analysis datum) is up to \pm 0.18 ISS fraction difference in a pressure layer then all variables accounted for here are within this. Moving forward the authors postulated that pressure level, geographical location (including St. Helena) and season were all within the British Isles dataset standard deviation and can be accounted for by one single s-shape. The variable which, while still within the standard deviation, showed the largest ISS fraction difference (up to \pm 0.1 ) from the mean was the pressure layer depth ( 50 and $100 \mathrm{hPa}$ ). Pressure layer depth is also likely to be the most important variable when using any mathematical model on different vertical resolution datasets. Therefore, for each pressure layer depth, different s-shapes were considered in the mathematical modelling exercise that followed.

The mathematical model presented used the distributions of the actual radiosonde observations in each average relative humidity bin. A standard deviation for each bin was calculated and it was assumed that within each bin the RHi observations followed a Gaussian distribution. Using these data an error function, based on the integral of the Gaussian distribution, was used to form a mathematical representation of the ISS fraction within any arbitrary thick pressure layer. More specifically the model used two standard deviation data-sub-sets, for both pressure layers (50 and $100 \mathrm{hPa}$ ). The model appears to represent the s-shaped function to within \pm 0.08 ISS fraction within a pressure layer when compared to the observation derived s-shapes for both thick pressure layers. This is within acceptable limits given the standard deviation of the British Isles dataset used. The modelled s-shaped curves rely on $\sigma_{u}$ and these data are produced from observations. However, it is proposed that the $\left(u, \sigma_{u}\right)$ dataset for the British Isles, for both 50and $100-\mathrm{hPa}$ pressure layers, can be used with the error function model for other geographical locations, pressure levels $(400-150 \mathrm{hPa})$, seasons and years. This model can be used, to represent ISS events, in modelled data where only low vertical resolution is available. This will be useful in understanding, and improving the global distribution, both observed and forecasted, of ice super-saturation.

The coarse horizontal and vertical resolution of climate models mean a single RHi value describes a grid box of, for example, $200 \mathrm{~km} \times 200 \mathrm{~km} \times 1 \mathrm{~km}$. Subgrid-scale variations of RHi are generally accounted for by cloud formation parameterisations which allow clouds to form at RHi values that are lower than cloud physics postulates. This is the equivalent to assuming that in one part of the grid box the $\mathrm{RHi}$ is such that a cloud can form while the grid-box mean RHi is still too low. The same logic holds true for contrail formation and contrail persistence, with the understanding that contrails will only persist when the atmosphere is ice supersaturated $(\mathrm{RHi}>100 \%)$. Therefore, in a climate model grid box (given an average RHi), the s-function model could be used to interpret the ice supersaturation content within a grid box depth. For example, applying the s-function to a grid box with an RHi of $80 \%$ would mean that $20 \%$ of the boxes depth is ice supersaturated, which describes the potential for contrail persistence.

A potential weak point of any long-term data analysis is caused by change of sensors or procedures, as for instance the change to RS92 in 2006. In Fig. 6 it is suspect that the s-shaped curve for 2006 is less steep than that of any previous year, throughout all stations. The change to the RS92 in that year might be the reason for this. As radiosonde data for later years (2007 to 2009) are now fully available the s-function should also be computed for these years. Another topic for further research is the extension of the investigation to more tropical radiosonde launch stations. The maps of ISS frequency provided by Spichtinger et al. (2003b) show that the tropics are not homogeneous with respect to ice supersaturation. In particular, St. Helena is already in a region that might by characterised by subsidence, hence has only few ISS occurrences. Other locations in the tropics show much higher probability of ice supersaturation. An analysis of more tropical radiosonde data is therefore strongly recommended.

Acknowledgements. The authors would like to thank NERC, QinetiQ and DLR for funding this research. Also, thanks go to members of the Centre for Atmospheric Science in Cambridge for their support and many useful comments. The study contributes to German projects UFO and CATS and to the European Network of Excellence ECATS. All three projects aim at environmentally compatible aviation, and the present study contributes especially to improved forecast of ice super-saturated regions which is a requirement for operational contrail avoidance measures. The authors thank the reviewers for their constructive comments.

Edited by: P. Spichtinger

\section{References}

Dickson, N. C., Gierens, K., Rogers, H. L., and Jones, R. L.: Vertical spatial scales of ice supersaturation and probability of ice supersaturated layers in low resolution profiles of relative humidity, in: Proceedings of the International Conference on Transport, Atmosphere and Climate (TAC-2), Aachen and Maastricht, 22-25 June 2009, in press, 2010.

Gettelman, A., Walden, V. P., Miloshevich, L. M., Roth, W. L., and Halter, B.: The global distribution of supersaturation in the upper troposphere from the Atmospheric Infrared Sounder, J. Climate, 19, 6089-6103, 2006a.

Gettelman, A., Walden, V. P., Miloshevich, L. M., Roth, W. L., and Halter, B.: Relative humidity over Antarctica from radiosondes, satellites, and a general circulation model, J. Geophy. Res., 111, D09S13, doi:10.1029/2005JD006636, 2006b. 
Gierens, K., Schumann, U., Helten, M., Smit, H., and Marenco, A.: A distribution law for relative humidity in the upper troposphere and lower stratosphere derived from three years of MOZAIC measurements, Ann. Geophys., 17, 1218-1226, doi:10.1007/s00585-999-1218-7, 1999.

Gierens, K. and Spichtinger, P.: On the size distribution of ice-supersaturated regions in the upper troposphere and lowermost stratosphere, Ann. Geophys., 18, 499-504, doi:10.1007/s00585-000-0499-7, 2000.

Gierens, K., Kohlhepp, R., Spichtinger, P., and SchroedterHomscheidt, M.: Ice supersaturation as seen from TOVS, Atmos. Chem. Phys., 4, 539-547, doi:10.5194/acp-4-539-2004, 2004.

Gierens, K., Kohlhepp, R., Dotzek, N., and Smit, H.: Instantaneous fluctuations of temperature and moisture in the upper troposphere and tropopause region, Part 1: Probability densities and their variability, Meteorol. Z., 16, 221-231, 2007.

Goff, J. and Gratch, S.: Low pressure properties of water from -160 to 212 F, Am. Soc. Heating and Ventilation, New York, USA, Tech. Rep. 52, 95-122, 1946.

Hoinka, K.: Mean global surface pressure series evaluated from ECMWF reanalysis data, Q. J. Roy. Meteor. Soc., 124, 22912297, 1998a.

Hoinka, K.: Statistics of the Global Tropopause Pressure, Mon. Weather Rev., 126, 3303-3325, 1998b.

Houghton, J.: The physics of atmospheres, 3rd edition, Cambridge University Press, Cambridge, UK, 2002.

Kahn, B. H., Liang, C. K., Eldering, A., Gettelman, A., Yue, Q., and Liou, K. N.: Tropical thin cirrus and relative humidity observed by the Atmospheric Infrared Sounder, Atmos. Chem. Phys., 8, 1501-1518, doi:10.5194/acp-8-1501-2008, 2008.

Kahn, B. H., Gettelman, A., Fetzer, E. J., Eldering, A., and Liang, C. K.: Cloudy and clear-sky relative humidity in the upper troposphere observed by the A-train, J. Geophys. Res., 114, D00H02, doi:10.1029/2009JD011738, 2009.

Lamquin, N., Stubenrauch, C. J., and Pelon, J.: Upper tropospheric humidity and cirrus geometrical and optical thickness: Relationships inferred from 1 year of collocated AIRS and CALIPSO data, J. Geophys. Res., 113, D00A08, doi:10.1029/2008JD010012, 2008.

Lamquin, N., Gierens, K., Stubenrauch, C. J., and Chatterjee, R.: Evaluation of upper tropospheric humidity forecasts from ECMWF using AIRS and CALIPSO data, Atmos. Chem. Phys., 9, 1779-1793, doi:10.5194/acp-9-1779-2009, 2009.

Maddy, E. S. and Barnet, C. D.: Vertical Resolution Estimates in Version 5 of AIRS Operational Retrievals, IEEE T. Geosci. Remote, 46, 2375-2384, 2008.

Miloshevich, L., Paukkunen, A., Vömel, H., and Oltmans, S.: Development and validation of a time-lag correction for Vaisala radiosonde humidity measurements, J. Atmos. Ocean. Tech., 21, 1305-1327, 2004.
Ovarlez, J., Gayet, J.-F., Gierens, K., Ström, J., Ovarlez, H., Auriol, F., Busen, R., and Schumann, U.: Water vapor measurements inside cirrus clouds in northern and southern hemispheres during INCA, Geophys. Res. Lett., 29, 16, doi:10.1029/2001GL014440, 2002.

Paukkunen, A.: Sensor heating to enhance reliability of radiosonde humidity measurements, in: 11th Int. Conf. On Interactive Information and Processing Systems for Meteorology, Oceanography, and Hydrology, Am. Meteorol. Soc., Dallas, Texas, USA, 103-106, 1995.

Rädel, G. and Shine, K.: Evaluation of the use of radiosonde humidity data to predict the occurrence of persistent contrails, Q. J. Roy. Meteor. Soc., 133, 1413-1423, 2007.

Spichtinger, P., Gierens, K., and Read, W.: The statistical distribution law of relative humidity in the global tropopause region, Meteorol. Z., 11, 83-88, 2002.

Spichtinger, P., Gierens, K., Leiterer, U., and Dier, H.: Ice supersaturation in the tropopause region over Lindenberg, Germany, Meteorol. Z., 12, 143-156, 2003a.

Spichtinger, P., Gierens, K., and Read, W.: The global distribution of ice-supersaturated regions as seen by the Microwave Limb Sounder, Q. J. Roy. Meteor. Soc., 129, 3391-3410, 2003b.

Spichtinger, P., Gierens, K., Smit, H. G. J., Ovarlez, J., and Gayet, J.-F.: On the distribution of relative humidity in cirrus clouds, Atmos. Chem. Phys., 4, 639-647, doi:10.5194/acp-4-639-2004, 2004.

Treffeisen, R., Krejci, R., Ström, J., Engvall, A. C., Herber, A., and Thomason, L.: Humidity observations in the Arctic troposphere over Ny-Ålesund, Svalbard based on 15 years of radiosonde data, Atmos. Chem. Phys., 7, 2721-2732, doi:10.5194/acp-7-2721-2007, 2007.

UK Meteorological Office: UK High Resolution Radiosonde Data, Internet, British Atmospheric Data Service (BADC), available at: http://badc.nerc.ac.uk/data/rad-highres/, last access: June 2009, 2006.

Vaughan, G., Cambridge, C., Dean, L., and Phillips, A. W.: Water vapour and ozone profiles in the midlatitude upper troposphere, Atmos. Chem. Phys., 5, 963-971, doi:10.5194/acp-5-963-2005, 2005.

Vömel, H., Selkirk, H., Miloshevich, L., Valverde-Canossa, J., Valdés, J., Kyrö, E., Kivi, R., Stolz, W., Peng, G., and Diaz, J.: Radiation dry bias of the Vaisala RS92 humidity sensor, J. Atmos. Ocean. Tech., 24, 953-963, 2007.

Wang, J., Cole, H., Carlson, D., Miller, E., Beierle, K., Paukkunen, A., and Laine, T.: Corrections of humidity measurement errors from the Vaisala RS80 radiosonde - Application to TOGA COARE data, J. Atmos. Ocean. Tech., 19, 981-1002, 2002. 